\title{
Las huellas ocultas: La Teología de la prosperidad en América Latina a la luz de sus orígenes ideológicos en el movimiento del Nuevo pensamiento
}

\section{The hidden traces: The Prosperity Gospel in Latin America in light of its ideological origins in the New Thought Movement}

Marco Antonio Quesada Chaves Escuela Ecuménica de Ciencias de la Religión

Universidad Nacional, Costa Rica marco.quesada.chaves@una.cr

\begin{abstract}
Resumen
En las últimas tres décadas, agrupaciones cristianas han logrado proyectarse e instalarse de manera paulatina en las estructuras políticas de varios países de América Latina, logrando ocupar diversas instancias gubernamentales para así impulsar sus propias agendas. Ante dicho fenómeno, resulta importante abordar de manera crítica e investigativa el discurso teológico que impulsan muchas de estos grupos y partidos políticos, el cual se conoce como la Teología de la prosperidad. En el presente artículo se realiza un sondeo histórico para rastrear lo que son sus orígenes ideológicos, los cuales tienen como una de sus principales fuentes el movimiento filosófico y espiritual del Nuevo pensamiento, surgido a mediados del siglo XIX en los Estados Unidos. De esta forma, se abre un cuestionamiento sobre si la Teología de la prosperidad es realmente una teología, al discutir y contrastar sus principales consignas desde una perspectiva histórica, teológica y crítica.

Palabras claves: Teología de la prosperidad, Nuevo pensamiento, Neo-pentecostalismo, ideología, política.
\end{abstract}




\begin{abstract}
In the last three decades, Christian groupings have managed to project and install themselves gradually in the political structures of several Latin American countries, managing to occupy diverse governmental instances in order to promote their own agendas. Given this phenomenon, it is important to critically and investigatively address the theological discourse that many of these congregations and political parties promote, which is known as the Prosperity Gospel. In the present article, a historical survey is carried out to trace what its ideological origins are, one of its main sources being the philosophical and spiritual movement of the New Thought, which emerged in the mid-nineteenth century in the United States. In this way, a question arises about whether the Prosperity Gospel is really theology, by discussing and contrasting its main slogans from a theological and critical perspective.
\end{abstract}

Keywords: Prosperity Gospel, New Thought, Neo-pentecostalism, ideology, politics.

\section{Introducción}

\section{Evangélicos, pentecostales y neo pentecostales en el contexto latinoamericano}

$\mathbf{T}$ Trazar el camino por el que va evolucionando la situación social, religiosa y sobre todo política en América Latina, no puede ignorar los atajos por los cuales diversas congregaciones protestantes se han incorporado a dicho panorama. Se trata sobre todo de iglesias evangélicas, pentecostales y neo-pentecostales. Por lo general, tiende a incluirse en la etiqueta de "evangélicos" a estas dos últimas agrupaciones, y otras como metodistas y presbiterianos, pero ello no es del todo preciso.

Dicha generalización terminológica puede dar lugar a muchos malentendidos, ya que existen diferencias históricas, políticas y teológicas entre ellas que no pueden pasarse por alto para comprender el fragmentado universo eclesial del protestantismo. Son diferencias que pesan entre quienes conforman dichas iglesias, por tanto, y por prudencia metodológica, se hablará de ellas por separado, con respeto a sus particularidades, $\mathrm{y}$ sin etiquetarlas a todas bajo el nombre de "evangélicas"; una recomendación que de hecho sugieren algunos como Moreno y Moreno (2017).

En el actual panorama político latinoamericano, sí es importante notar que la teología desarrollada en algunas iglesias evangélicas, pentecostales y sobre todo neo-pentecostales, es la que, por lo general, está en la base de varios partidos políticos cristianos, los cuales han ganado una importante presencia en la esfera electoral, sobre todo en países como Guatemala, Costa Rica, Colombia y últimamente, Brasil. Se trata de la Teología de la prosperidad, que presenta como fundamentos de la vida espiritual a: la riqueza, la prosperidad 
material, financiera, la salud física así como el estatus social. Esto sin embargo, no es una realidad nueva ni medianamente sorpresiva, sino que es resultado de una serie de procesos históricos, sociales y religiosos que vienen gestándose desde el siglo antepasado.

Anglicanos, presbiterianos, metodistas y otros fueron de los primeros grupos protestantes que se instalaron en la región a través de la llegada de diplomáticos y comerciantes europeos. Su identidad y creencias, más toleradas que aceptadas en una región abrumadoramente católica como lo era América Latina en aquel momento, estuvo también protegida por los tratados comerciales que los nacientes países concretaron con el Imperio británico y otras naciones europeas (Lynch, 2012).

No obstante, si bien la instalación del protestantismo en sus diversas variantes estuvo precedida por la llegada de inmigrantes europeos, su avance y difusión en las sociedades latinoamericanas también se vio favorecido por las transformaciones y conflictos sociopolíticos acaecidos entre los siglos XIX y XX. Schäfer (2009) explica por ejemplo cómo a los pocos años de independizadas algunas naciones, numerosas iglesias aprovecharon la ruptura entre una clase colonial dominante, ligada principalmente a la Iglesia católica, y una naciente clase social conformada por comerciantes liberales, entre quienes el protestantismo llegó a ser muy aceptado, por la afinidad entre los valores liberales y la teología luterana de la justificación por la fe, aceptada y predicada por la mayoría de estas iglesias.
Lo anterior se vio reforzado por una masiva actividad evangelizadora realizada por las mismas iglesias, cuya actividad de proyectarse en lo social y cultural se dio sobre todo en el ámbito educativo (Barrera, 2006). Ello logró suplir una demanda de sentido religioso entre algunos estratos poblacionales, lo que allanó el terreno para que surgieran y se expandieran otras iglesias como las pentecostales.

El pentecostalismo; fenómeno religioso complejo y abordado desde varias disciplinas como la psicología, la sociología o la antropología (Mansilla, 2009), sigue constituyendo un desafío por su diversidad. En general, estas iglesias se caracterizan por una teología que enfatiza la importancia del bautismo en nombre del Espíritu Santo, como tercera persona de la Trinidad, que adquiere un peso determinante en la vida espiritual. Esto ha dado lugar a una forma de culto muy carismático, cargado de intensidad emocional, manifestaciones extáticas y de curaciones físicas (Garrard-Burnett, 2011). Por otra parte, en su eclesiología no existen mediaciones, es decir; entre el sujeto y Dios no existen instituciones o ritos que influyan en la relación. Su acceso a lo sagrado, afirma Mansilla (2009), es directo, lo que provee de una experiencia religiosa fuertemente subjetiva.

El rol del pentecostalismo sería fundamental en la historia religiosa latinoamericana, pues hacia finales del siglo XIX y la primera parte del XX, aparece en la escena social, afincándose de manera progresiva entre los estratos más desfavorecidos y depauperados. Schäfer (2009) lo sintetiza de la siguiente manera: 
Son los períodos con cambios sociales drásticos en los que el pentecostalismo más crece: comienza con la industrialización de los años 40 en las ciudades y las minas del sur y con la mecanización de la agricultura durante los años 50 en Centroamérica y sigue con las guerras centroamericanas así como con los cambios sociales en relación a la neoliberalización de las economías y sociedades en los años 90. (p. 48)

En este breve sondeo, una corriente devenida del pentecostalismo empieza a cobrar importancia a inicios de los años 60 del siglo pasado, sobre todo en los Estados Unidos; se trata del neo-pentecostalismo, término más empleado por quienes se dedican al estudio de lo religioso que por quienes integran dichas iglesias. Como una variante relativamente identificable del pentecostalismo, las iglesias neo-pentecostales se caracterizan también por un énfasis en lo carismático, en el que sus pastores son ungidos por el Espíritu Santo, y por una cualidad muy peculiar: un énfasis en que las bendiciones de Dios se alcanzan por donaciones monetarias así como por una fe basada en el pensamiento positivo. La prosperidad financiera, material, y el bienestar físico, serían entonces la manifestación de tales bendiciones.

Por esta última característica, en América Latina, su presencia social se ha dado, sobre todo, entre las clases medias y altas que van ascendiendo, pues respondían a las demandas de sentido de un sector social conformado por profesionales de unas sociedades que, durante la mayor parte del siglo, se estuvieron industrializando. El poder adquisitivo que estas congregaciones llegaron a poseer permitió el desarrollo de organizaciones sólidas, que van desde pequeñas iglesias, hasta las muy conocidas "mega-iglesias".

Empero, tanto unas como otras iglesias de distinta orientación debieron su exitosa presencia entre diversos sectores de las sociedades latinoamericanas sobre todo a una combinación de las circunstancias históricas y sociopolíticas, pero también a una ingente actividad proselitista. En general, se logró suplir la necesidad de una experiencia religiosa más personal, libre del tener que afiliarse a instituciones y tradiciones, como es propio en el mundo contemporáneo.

Cabe comprender que, dadas las difíciles circunstancias vividas en muchos países durante la segunda mitad del siglo XX, la adversidad sufrida por muchas personas llevó a una pérdida del sentido de la vida, ante la tragedia y los males devenidos por problemáticas como la pobreza, la desintegración familiar, el desempleo, los conflictos armados que azotaron sobre todo a Centroamérica durante la segunda mitad de siglo, así como por las dictaduras militares que se instauraron en varios países de Suramérica durante el mismo período.

Las iglesias pentecostales, como se ha mencionado, lograron insertarse entre sectores depauperados, donde las precarias condiciones socioeconómicas se vieron apaciguadas al ser acogidas por muchas personas en iglesias que predicaban una visión apocalíptica del mundo, basada en la doctrina de la guerra espiritual. Esta concibe el mundo y la vida de cada persona como el escenario de un enfrentamiento entre Dios y Satanás. Destaca también en 
esta visión la teología del "rapto", donde se interpretan las difíciles circunstancias históricas, sociales y políticas como indicadores de un inminente fin de los tiempos. Al darse la segunda venida de Jesucristo, quienes murieron en santidad resucitarán, mientras que los vivos serán arrebatados hasta los Cielos. Todo esto en el nivel psicosocial permitió una recuperación de la dignidad personal ante la adversidad, así como una fuerte integración grupal.

El neo-pentecostalismo por su parte, llegó a desarrollar una importante presencia en países como Guatemala, ya que logró una amplia aceptación entre los sectores más acaudalados y poderosos (Schäfer, 2009). Pero no fue sino hasta la década de los ochenta cuando se puede apreciar tanto un crecimiento acelerado de estas iglesias, como una importante presencia política, cuyas bases sociales se estuvieron consolidando durante las décadas anteriores.

Para Córdova (2014), es a partir de los 80, donde junto a la caída de varias dictaduras militares en la región y la consolidación de los partidos políticos como mediadores entre el Estado y la sociedad, que distintas iglesias protestantes empiezan a proyectarse en política, a través de varias organizaciones y partidos por medio de los cuales, poder canalizar su agenda ideológica.

Esto representa algo inusitado, ya que según Barrera (2006), la mayoría de iglesias protestantes en América Latina nunca se interesaron por incursionar activamente en la política, al seguir, muchas de ellas, la doctrina luterana de los dos reinos (Mansilla, 2009), en la que Dios gobernaría el reino terrenal a través de los poderes seculares, y el reino de los cielos a través de la gracia. Pero es el movimiento neopentecostal -cuya base social tenía un fuerte poder adquisitivo- el que empieza a insertarse en las estructuras políticas, involucrándose luego otras agrupaciones como los evangélicos.

De esta manera, llegan a formar parte de una globalización religiosa que ha alcanzado proporciones importantes en países como Brasil, donde son algunas iglesias evangélicas, pentecostales y neo-pentecostales las que tienen una presencia más activa en la política, lo que quedó demostrado con la elección del actual gobierno brasileño.

En la presente exposición histórica y teológica, cabe tener presente que el crecimiento de las iglesias neo-pentecostales en América Latina está ligada al auge de dichas congregaciones en los Estados Unidos; un fenómeno que posterior a la mitad del siglo pasado se ha vinculado con el surgimiento del neoliberalismo y su implementación en varios países de Occidente durante este período histórico. Fenómenos como los "teleevangelistas" en Estados Unidos durante la década de los años 80 hasta la actualidad, no hizo sino consolidar la presencia del neo-pentecostalismo en América Latina como una corriente cristiana que legitimara las ideas neoliberales y los principales valores del capitalismo.

A través del desarrollo tecnológico de los medios de comunicación masiva, se abrieron las puertas para que varios pastores difundieran sus prédicas en el nivel internacional, al amasar importantes fortunas por medio de las ofrendas y donaciones que los fieles daban, a la espera de una retribución 
divina. Se extendió así la influencia y presencia de dichas iglesias, cuyo discurso teológico es uno muy particular; ha calado profundamente no solo en un amplio sector cristiano de la sociedad estadounidense, sino también entre los cristianos protestantes de América Latina. Sin embargo, rastrear e identificar sus orígenes ideológicos, más que teológicos, si es que los hay, es una tarea pendiente de elaborar.

\section{La Teología de la prosperidad y sus rasgos ideológicos}

Al tomar en cuenta el contexto histórico, expuesto anteriormente, es notable que dentro de la creciente diversidad religiosa de lo religioso que se ha dado en América Latina desde finales del siglo XX hasta la actualidad, el neo-pentecostalismo sea probablemente la corriente religiosa que más rápidamente ha venido creciendo en el mundo, igualada solo por el Islam (García-Ruiz y Michel, 2014).

Es una corriente que se ha integrado de manera exitosa a las nuevas dinámicas socioeconómicas suscitadas por los procesos de secularización, globalización, desterritorialización, construcción de nuevas identidades y formas de pertenencia en el nivel comunitario, las cuales muchas veces van más allá de las instituciones religiosas y del Estado como entidades que definen la identidad religiosa y cultural.

En Bauman (2006) y su teoría de la modernidad líquida, García-Ruiz y Michel (2014) plantean que el neo-pentecostalismo es el perfecto ejemplo de cómo lo religioso también ha adoptado una forma líquida en las sociedades postmodernas.
El neo-pentecostalismo es una manifestación de lo religioso que se desliga de un modelo tradicional, místico, ortodoxo e institucional de cristianismo como por ejemplo, el de la Iglesia católica.

Las iglesias de orientación neo-pentecostal han sabido ajustarse al fenómeno de privatización de lo religioso que se ha venido dando en las sociedades occidentales (Beck, 2013), donde la experiencia religiosa se convierte en algo centrado en el individuo, sus deseos e inclinaciones, antes que responder a la voluntad y alteridad de un Dios trascendente. De acuerdo con Mansilla (2008, citado por Mansilla 2009), la secularización que está detrás de este fenómeno de la privatización de lo religioso impactó más profundamente en las iglesias neo-pentecostales que en las pentecostales:

El neopentecostalismo ha desviado su atención de los símbolos religiosos del pentecostalismo clásico, adecuando su discurso a la sociedad presente; poniendo en primer lugar su atención en la tierra y en el presente. Así los creyentes, predicadores y cantantes- artistas pentecostales resaltan: la alegría religiosa; el egocentrismo; el mito de la prosperidad; el creer sin asistir mayormente a los templos; evitan los sacrificios religiosos de antaño; e interpretan una liminalidad de las fronteras entre lo sagrado y lo profano como una nueva forma de entender la vida religiosa. (pp. 33-34)

Esta porosa frontera entre lo sagrado y lo profano es la que está en la base de su inserción en la política, pues socialmente, tanto los pastores neo-pentecostales como sus congregaciones establecen lo 
que Moreno y Moreno (2017) consideran que es una correlación teleológica entre lo religioso y lo político, y vale agregar, lo económico-financiero.

La estructura de las congregaciones muchas veces emula un modelo empresarial, acuerpado por una industria literaria de autoayuda con un fuerte mercadeo (marketing), que les permite identificar y suplir las principales necesidades psicológicas, emocionales y espirituales en los individuos. El estilo de sus cultos y celebraciones es, por lo general, uno que incorpora elementos estéticos del espectáculo, lo que fomenta una experiencia religiosa altamente estimulante, centrada en lo emocional, y no tanto en lo contemplativo o en el recogimiento interior. Aunado a esto, abundan reportes de manifestaciones carismáticas como el hablar en lenguas, o bien las curaciones milagrosas.

Acá se trata no tanto de entrar a debatir sobre la veracidad o no de tales fenómenos extraordinarios, o de su dimensión teológica, sino resaltar que el trasfondo en el que ocurren es uno donde lo religioso se convierte en un bien mercantil. El tipo de experiencia que se fomenta es algo que se ofrece como un producto, el cual se promociona por medio de un amplio abanico de ofertas espirituales, de autoayuda y demás, que permitan darle un sentido a la vida actual. Las iglesias entonces adoptan la lógica imperante en las sociedades de mercado, la del consumo:

En esta lógica, el actor religioso es simultáneamente un actor económico, formado y sometido a las reglas de la economía mundializada. Difunde al mismo tiempo la mercancía que introduce en el mercado y de la que asume la promoción y la difusión, los valores sobre los que reposa el buen funcionamiento del mercado, su aceptación y la de sus reglas como espacio legítimo de organización de la vida colectiva. Se presenta por lo tanto como siendo además un actor religioso y económico, un actor ideológico, lo cual lo constituye de facto potencialmente en actor político. (García-Ruiz y Michel, 2014, pp. 54-55)

Es en esta dinámica donde entra la Teología de la prosperidad; pues es el corpus ideológico -más que teológico- que fundamenta, legitima y da sentido a esta forma de asumir la fe y la identidad cristiana en las sociedades de consumo, identidad que es también política. También conocida como Evangelio de la prosperidad o Prosperity Gospel, las iglesias que adoptan esta ideología no desarrollan sus actividades en un ámbito meramente religioso y personal, sino que se extienden también a lo económico, y se proyectan hacia lo político, sin que ello implique un contrasentido moral o teológico. Por supuesto, evitan incorporar en su discurso una crítica muy marcada hacia el sistema socioeconómico imperante, pues ello implicaría caer en un contrasentido.

De esta forma, y para propósitos de definir los conceptos, vale afirmar que el de "Teología de la prosperidad" comporta una serie de problemáticas en cuanto al significado del término, pues dicha teología es fundamentalmente un discurso ideológico, que interpreta el Evangelio en función de los valores capitalistas de la prosperidad financiera, el individualismo, el bienestar físico y el consumo de bienes materiales. 
Es frecuente que se adopte una perspectiva triunfalista de la fe cristiana, centrada no tanto en la realidad sacrificial y redentora de Cristo muerto y resucitado, sino en el poder del individuo para inclinar la balanza de la vida en favor de sus intereses, a través del pensamiento positivo y las donaciones monetarias. En este sentido, es también una perspectiva materialista, pues tanto la prosperidad económica como la salud física se consideran reflejo de la realidad espiritual. Por este motivo, algunos como Piedra (2005) la consideran "una interpretación de la fe cristiana que percibe las situaciones humanas de enfermedad y pobreza material como resultado de una relación deficiente con Dios" (p. 3).

Si bien es una ideología que se ha desarrollado sobre todo en el neo-pentecostalismo, cuya máximo símbolo es la ostentosidad de sus "mega-iglesias", la Teología de la prosperidad también ha venido siendo adoptada por pequeñas iglesias, algunas medianamente identificables como evangélicas y pentecostales. Se afirma esto de manera tentativa, pues según Bowler (2018), uno de los rasgos distintivos y más complicados de entender en estas iglesias y sus líderes, es su reticencia a identificarse en alguna de las numerosas corrientes protestantes de la actualidad, lo cual vuelve dificultoso el elaborar una taxonomía precisa.

En dicho contexto, surgen entonces algunas interrogantes, ¿cómo es que la teología de la prosperidad ha llegado a desarrollar un discurso ideológico tan apelativo para millones de cristianos? ¿Cuáles son los orígenes históricos e ideológicos de esta forma de entender la fe cristiana, de este discurso? Son preguntas cuyas respuestas aún están en proceso de ser indagadas. Por ende, rastrear los orígenes históricos e ideológicos es buen punto para comenzar.

\section{Sus orígenes históricos: el movimiento del Nuevo pensamiento}

Los orígenes históricos de la Teología de la prosperidad se sitúan en Norteamérica durante la segunda mitad del siglo XIX e inicios del XX, siendo así que su génesis es fruto de una serie de corrientes de pensamiento que surgieron con mucha fuerza, al competir entre sí por la atención mediática del momento. Bowler (2018), en un notable estudio sobre los orígenes de la Teología de la prosperidad en la sociedad estadounidense, considera que tres son sus principales fuentes: el pentecostalismo, el movimiento del Nuevo pensamiento o New Thought, y una interpretación del Evangelio muy ligada a los valores culturales norteamericanos del pragmatismo, el individualismo y la movilidad social ascendente.

Tanto la primera como la tercera fuente son más conocidas hasta hoy en día para rastrear y entender lo que ofrece y vende la teología de la prosperidad, pero sobre la segunda poco se ha investigado en América Latina, en el sentido de conocer cómo las ideas promovidas por el movimiento del Nuevo pensamiento en los Estados Unidos no solo han influido en las congregaciones pentecostales y neopentecostales de esa nación, sino también en numerosas iglesias de la región latinoamericana e incluso, en otras formas de religiosidad postmodernas como la llamada Nueva era. 
El surgimiento del movimiento del Nuevo pensamiento se da a inicios-mediados del siglo XIX. La sociedad estadounidense posterior a la Guerra civil (1861-1865) era un hervidero de movimientos espirituales, ocultistas, filosóficos y demás que poblaron el entorno social, en la que se conoce como la Era dorada. Fue una época en la que se promovían, sobre todo, ideas individualistas y pragmatistas centradas en el arte del perfeccionarse a sí mismo, vislumbrándose, de esta forma, los primeros indicios de la literatura de autoayuda que tan en boga está hoy en día.

Este conglomerado de ideas, por supuesto, influyó en muchos pensadores cristianos y sus congregaciones. Surgieron así agrupaciones como la Ciencia cristiana o Christian science, fundada por Mary Baker Eddy (1821-1910), quienes interpretaban la relación del ser humano con Dios desde el llamado "poder mental" (Bowler, 2018). Es decir, el vínculo con Dios no estaría centrado en su voluntad ni en el misterio de su trascendencia, sino en el ser humano, en su perfectibilidad, así como en su capacidad para influir en la realidad espiritual a través de la oración, el pensamiento positivo y la imaginación.

Por otra parte, para esta pensadora, como para otros líderes cristianos de ese tiempo, el núcleo del mensaje de Jesucristo sería el conocimiento, y la manera de crecer espiritualmente a través de la llamada ciencia mental del momento. Por ejemplo, cuestiones teológicas como la salvación no se entendían como una realidad trascendente y redentora, como algo dado por Dios en su misericordia y gratuidad, sino como un medio para que la humanidad desarrollase su potencial. Por tanto, la fe cristiana pasó a ser interpretada según los cánones filosóficos de la modernidad, donde es el antropocentrismo, y no el teocentrismo, lo que prima.

En este contexto surge el movimiento del Nuevo pensamiento, hacia la década de 1880 , el cual tuvo en los trabajos de Phineas Parkhurst Quimby (1802-1866) sus bases teóricas, las cuales parten del calvinismo (Haller, 2012). Quimby, un inventor y autodenominado sanador, fue quien más desarrolló la idea del poder mental, la cual se refiere sobre todo a la capacidad de la mente para sanar el cuerpo, algo que de hecho fue el mayor interés del movimiento en sus inicios.

La corriente se remite a la influencia de figuras más lejanas como el teólogo luterano Emanuel Swedenborg (1688-1772), y más contemporáneas de aquel momento como el poeta Ralph Waldo Emerson (1803-1882). Los escritos espirituales y metafísicos del primero, y la poesía trascendentalista del segundo inspirarían a Quimby y sus seguidores a construir una nueva visión del ser humano. Así, para Bowler (2018), tres son los pilares de este movimiento:

a) Una antropología ascendente. Se trata de una unidad esencial entre Dios y el ser humano, donde se manifiesta un importante optimismo en torno a las capacidades de la persona. La separación de lo divino, tan enfatizada en el pensamiento luterano, es ahora considerada no como una realidad imposible de superar por la corrupción de la naturaleza humana, sino que la diferencia entre lo divino y lo humano es solo de grado. 
b) La primacía de la realidad espiritual. En otras palabras, el mundo espiritual constituye el fundamento de la realidad, mientras que lo material es una proyección de la mente; una idea que de hecho acerca a este movimiento con el pensamiento filosófico de religiones orientales como el hinduismo y el budismo.

c) El poder generador del pensamiento positivo. Esta es una de las principales ideas, de las más difundidas por los adeptos de la Teología de la prosperidad. Parte de la premisa de que las personas comparten el poder creador de Dios a través del pensamiento, por tanto, se pueden cambiar las circunstancias a través del pensamiento positivo, sobre todo para modificar la situación financiera y material. Warren Felt Evans (1817-1889), el primer autor formal del Nuevo pensamiento, explicaba por ejemplo que la enfermedad es un fenómeno que se origina en el desequilibrio, en el pensamiento incorrecto, negativo. Ello como se aprecia, no es del todo extraño para el lector actual, pues dicha idea está en la base de una amplia gama de obras de autoayuda y del conglomerado de corrientes religiosas de la Nueva era.

Así, la evolución de este movimiento a finales del siglo XIX y el transcurso del $\mathrm{XX}$ estuvo marcada por varias transformaciones en su discurso, que fue penetrando cada vez más en el imaginario social de los estadounidenses. Era natural y una cuestión de tiempo antes de que algunos pastores protestantes comenzaran a incluir la prosperidad material y el "éxito personal" en sus prédicas. Emma Curtis Hopkins (1849-1925) fue una figura clave en esta transición; teóloga, líder espiritual y hasta considerada profetiza, su papel fue fundamental para que, hacia la década del 90 del siglo XIX, el movimiento experimentara un progresivo viraje en su misión.

Del cultivo de la salud por medio del poder mental se pasa a incluir la prosperidad, el éxito y la abundancia material como manifestaciones del pensamiento positivo, como signo de la unión con Dios. Otra figura importante, en este sentido, fue el pastor bautista Russell H. Conwell (18431925), quien predicaba un evangelio de la riqueza, el cual reproducía esa simbiosis entre la ética protestante y el capitalismo que el conocido sociólogo Max Weber ya apuntaba en su obra La ética protestante y el espíritu del capitalismo, publicada entre 1904 y 1905.

Fue este un cambio que a criterio de Bowler (2018) sería definitivo, pues después de las dos guerras mundiales, la situación de abundancia material y prosperidad económica en la sociedad estadounidense hacia la década de los 50 fomentó más la presencia de las ideas del Nuevo pensamiento. Tal contexto propició que varios evangelistas pentecostales comenzaran a predicar entre las décadas de los 40 y los 50 un discurso cristiano que anunciaba bendiciones materiales, prosperidad financiera, y la importancia del poder mental para conducirse por la vida con una fe altamente espiritual.

La evolución de esta tendencia sería decisiva para que hacia los años 70-80 el neo-pentecostalismo y la Teología de la prosperidad despegaran no solo en la sociedad estadounidense, sino que también 
fuesen exportadas a América Latina. Las ideas subyacentes del Nuevo pensamiento, que dieron forma a muchos de los planteamientos del discurso ideológico de la prosperidad, mantuvieron su presencia.

Actualmente, y según Haller (2012), el movimiento del Nuevo pensamiento se perpetúa a través de nuevas organizaciones e iglesias, las cuales ordenan ministros, quienes a su vez buscan establecer sus propias congregaciones y asociaciones. Una de las más populares representantes contemporáneas de las ideas de este movimiento es la presentadora de televisión Oprah Winfrey, quien aparte de ser conocida por su programa televisivo The Oprah Winfrey Show, es propietaria de un canal de radio, un club de libros y una revista, entre otros medios de comunicación masiva. Para Haller (2012), figuras como Oprah han adquirido un alcance mediático internacional, al promover una religiosidad ecléctica que combina perspectivas idealistas y una versión "mística" del concepto del empoderarse a través del pensamiento.

Autoras como Rhonda Byrne, con su famosa película $E l$ secreto, lanzada en el año 2006, y luego complementada por el libro denominado El poder, publicado en el año 2010, predican la llamada "Ley de la atracción". Esta plantea que todo aquello que ocurre en la vida de una persona tiene su causa en la atracción mental. Es decir, lo que alguien piensa y mantiene en su mente, eso es lo que atraerá a su vida. La supuesta ley entonces, es presentada como el mayor secreto del Universo, el cual es una especie de cuasi deidad que responde a los deseos y pensamientos individuales, sean estos positivos o negativos.
Podría considerarse que incorpora elementos de la doctrina hinduista y budista del Karma, y lo trasplantan al pensamiento occidental-norteamericano.

Así, para Haller (2012), la influencia de este movimiento sincrético de carácter metafísico ha sido decisiva en la cultura y la religiosidad estadounidense, al moldear la mentalidad de un amplio sector de la sociedad. Sus principales pensadores a mediados del siglo XIX e inicios del XX, se vieron atraídos por las emergentes ciencias médicas como la neurología, la nefrología y por prácticas terapéuticas como el hipnotismo, que elabora una mezcla entre los conceptos de esas disciplinas y la fe cristiana, interpretada en clave individualista y espiritualista. Dicho sincretismo ha ido evolucionando paulatinamente hasta la actualidad, al incorporar elementos conceptuales de disciplinas científicas como la física cuántica, y de religiones como el budismo, específicamente las escuelas Zen y tibetana.

\section{Recapitulaciones críticas a partir de la perspectiva de William James}

Hacia inicios del siglo XX, cuando el movimiento del Nuevo pensamiento estaba en su apogeo, el filósofo y psicólogo estadounidense William James (1842-1910), en su conocida obra Las variedades de la experiencia religiosa, identifica al movimiento como la "Religión de la mentalidad sana" (trad. en 1987, p. 77).

En la mencionada obra, si bien mostró interés por el movimiento, no se identificó con él, sino que analizó de manera crítica varias ideas contenidas en los escritos de 
sus promotores, y cómo estas, entre otras características, difieren abiertamente de doctrinas cristianas fundamentales. Estas discrepancias serían las que se encuentran en la base de lo que luego llegaría a ser la Teología de la prosperidad. Vale la pena por ello, analizar brevemente tres de ellas:

a) Sobre la condición humana. Tal y como lo identifica Bowler (2018), James (trad. en 1987) también notó que en la antropología ascendente del movimiento se hallaba un punto de desencuentro con la concepción cristiana del ser humano. James (trad. en 1987) destacó esta contradicción en el discurso de los seguidores del Nuevo pensamiento, citando fragmentos de obras conocidas del momento:

\begin{abstract}
Although the disciples of the mind-cure often use Christian terminology, one sees from such quotations how widely their notion of the fall of man diverges from that of ordinary Christians. Their notion of man's higher nature is hardly lees divergent, being decidedly pantheistic. [Aunque los discípulos de la cura de la mente a menudo usan terminología cristiana, se puede ver en tales citas cuán ampliamente difiere su noción de la caída del hombre de la de aquellos cristianos comunes. Su noción de la naturaleza superior del hombre es difícilmente divergente, siendo decididamente panteísta.] (pp. 96-97)
\end{abstract}

La omisión de la teología del pecado original, de la fragilidad de la naturaleza humana así como de la tendencia al mal, conecta directamente este punto con el tercero, y es una de las principales lagunas del Nuevo pensamiento. Los planteamientos del pensador estadounidense son importantes puesto que ya desde ese mismo momento cuestionó cómo los seguidores del movimiento presentaban sus ideas bajo un ropaje cristiano, cuando en realidad no tienen una fundamentación teológica en las principales verdades de fe del Cristianismo, compartidas tanto por protestantes, como por católicos, y ortodoxoorientales. Se trataría más bien de un sincretismo de creencias religiosas cristianas y orientales, ideas filosóficas y biomédicas en boga en aquel momento, y elucubraciones propias de los líderes de dicho movimiento. En la antropología ascendente de este movimiento, mencionada anteriormente, James (trad. en 1987) identifica elementos de la "mística cristiana, de un idealismo trascendental, de vedantismo, y de la psicología moderna del ser subliminal" (p. 97).

b) Concepción de la fe. Para James (trad. en 1987), seis son las fuentes principales de las ideas del movimiento: La Biblia, el trascendentalismo de Ralph Waldo Emerson, el idealismo de Berkeley, el espiritismo, el evolucionismo optimista y el hinduismo. Según Haller (2012), todas estas fuentes tienen la misma idea en común: la de una creencia intuitiva en el poder salvador de las actitudes mentales saludables. Esto difiere notablemente de la concepción bíblica y cristiana de la fe, en tanto se la entiende como la confianza y entrega a la voluntad de Dios a lo largo de la vida. En el Nuevo 
pensamiento, así como posteriormente en la Teología de la prosperidad, la fe es vista como una especie de poder del cual dispone el ser humano para inclinar la balanza de los eventos de la vida en su favor. En sí, puede considerarse que se sustituye la fe por el "poder mental". Si bien James (trad. en 1987), en tanto psicólogo y filósofo, consideraba que la mente tenía un rol importante en el estado de salud así como en el desarrollo de la enfermedad, no llegó a suscribirse al sistema de creencias del movimiento.

c) Perspectiva sobre el problema del mal. Otra de las ideas predominantes en los grupos del Nuevo pensamiento, ya identificadas por James (trad. en 1987), era el poco tratamiento filosófico y teológico del problema del mal, el pecado y el arrepentimiento. De hecho, en la perspectiva de Mary Baker Eddy y su Ciencia cristiana, considerada por James como la más radical, el mal ni siquiera es visto como un problema en sí, sino como un hecho de la existencia que simplemente se constata, y al cual se le presta poca atención.

Dicha perspectiva del mal, muy ligada al pragmatismo característico de la cultura estadounidense, es poco profunda en el nivel teológico, y ha llegado a ser uno de los rasgos distintivos tanto de la Teología de la prosperidad predicada en numerosas iglesias neo-pentecostales, como inclusive de muchas ideas de la Nueva era.

Lo anterior reafirma el cuestionamiento sobre el porqué resulta difícil considerar a la Teología de la prosperidad como una teología, pues una temática fundamental en toda teología cristiana, ya sea de raigambre protestante o católica, es el tratamiento y la consideración del mal como un problema, como un misterio que forma parte de la realidad del ser humano. Lo anterior ha sido fundamental en prácticamente toda la historia de la teología cristiana, desde los primeros escritos apostólicos, el período patrístico, hasta los teólogos medievales, al pasar inclusive por teólogos protestantes como Lutero y Calvino.

A raíz de lo sondeado y discutido hasta el momento, puede apreciarse que en el trasfondo de la Teología de la prosperidad existe una serie de corrientes religiosas, metafísicas y filosóficas cuyos elementos en última instancia no son propiamente cristianos, sino que conforman un discurso ideológico revestido de teología, el cual en su ulterior evolución desarrolló la idea de que el poder mental y los pensamientos positivos atraen la riqueza y las bendiciones de Dios.

Garrard-Burnett (2011), afirma que la ecuación que une la fe con las donaciones monetarias y la prosperidad material es un fenómeno que tiene larga data en varios sectores protestantes estadounidenses, siendo así que la confianza en Dios es vista como un medio para ser bendecido con dinero y prosperidad material, así como salud física.

Como ha podido apreciarse, el movimiento del Nuevo pensamiento constituye una de sus principales fuentes; movimiento que a su vez, bebe de una serie de corrientes religiosas, poéticas y filosóficas particulares. En sí, tanto el Nuevo pensamiento como la Teología de la 
prosperidad son un producto típicamente moderno, en cuanto que espiritualizan el paradigma antropocéntrico de la presente época, así como los principales valores y prácticas del capitalismo.

Es una interpretación de la fe cristiana que según algunos de sus mayores críticos, efectivamente declina considerar la importancia de la realidad socioeconómica, y su influencia en el sufrimiento y la enfermedad como problemas teológicos, filosóficos y morales. En este sentido, es una forma de perpetuar el estado actual de la sociedad, con toda su desigualdad y problemáticas.

De esta forma, el presente artículo es un intento por reconstruir algunas de las bases ideológicas de dicho discurso, y así allanar el camino con el objetivo de que se planteen cuestionamientos críticos desde la Teología católica en posteriores investigaciones. Para entender a la llamada Teología de la prosperidad y su papel en el acelerado crecimiento e influencia de algunos sectores neo-pentecostales en la sociedad y la política latinoamericana, es preciso remontarse a su origen histórico; a su evolución intelectual a lo largo del último siglo y medio.

\section{Referencias}

Bauman, Z. (2006). Modernidad líquida. Buenos Aires: Fondo de Cultura Económica de Argentina.

Barrera, P. (2006). Evangélicos y política electoral en América Latina. Un estudio comparativo entre Brasil y Perú. Si Somos Americanos, Revista de Estudios Transfronterizos 8(1), 63-81. Recuperado de: https:// dialnet.unirioja.es/descarga/articulo/4875520.pdf

Beck, U. (2013). El Dios personal: la individualización de la religión y el "espíritu" del cosmopolitismo. Barcelona: Editorial Paidós.

Bowler, K. (2018). Blessed: A History of the American Prosperity Gospel. EE. UU.: Oxford University Press.

Córdova, J. (2014). Viejas y nuevas derechas religiosas en América Latina: los evangélicos como factor político. Nueva Sociedad 254, 112-123. Recuperado de: https://nuso.org/media/ articles/downloads/4073_1.pdf

García-Ruiz, J., Michel, P. (2014). El Neopentecostalismo en América Latina. Contribución a una antropología de la mundialización. Sociedad y Religión 41(24), 43-78.

Garrard-Burnett, V. (2011). A vida abundante: A Teologia da Prosperidade na América Latina. Historia: Questões \& Debates 55, 177-194. Recuperado de: https://revistas.ufpr.br/ historia/article/view/26546/17694

Haller, J. (2012). The History of New Thought: From Mind Cure to Positive Thinking and the Prosperity Gospel. EE. UU.: Swedenborg Foundation Press.

James, W. (trad. en 1987). Writings 19021910. New York: Literary Classics of the United States, Inc.

Lynch, J. (2012). Dios en el Nuevo Mundo: una historia religiosa de América Latina. Barcelona: Crítica.

Mansilla, M. (2008). Pluralismo, subjetivización y mundanización. El impacto de la secularización en el 
neopentecostalismo chileno. Revista Polis 19, 1-17. Recuperado de: https://journals .openedition .org/ polis/3955

Mansilla, M. A. (2009). Pentecostalismo y pobreza. Revista Cultura y Religión, 21-42. Recuperado de: https:// dialnet.unirioja.es/descarga/articulo/3088689.pdf

Moreno, C., Moreno, M. (2017). Entre la Teología del reino y la Teología de la Prosperidad: Aproximación al discurso político-religioso de las iglesias pentecostales en Caldas. Virajes Antropología Social 19(1), 209-227. Recuperado de: http://vip. ucaldas.edu.co/virajes/downloads/ Virajes19(1)_11.pdf
Piedra, A. (2005). Origen, desarrollo y crítica de la prosperidad. Espiga 11, 1-12. Recuperado de: https:// dialnet.unirioja.es/descarga/articulo/5339990.pdf

Schäfer, H. (2009). La generación del sentido religioso. Observaciones acerca de la diversidad pentecostal en América Latina. En Chiquete, D. (Ed). (2009). Voces del pentecostalismo latinoamericano III: Teología, historia, identidad, concepción. Chile: EMW/CETELA. 